\title{
O QUARTO CENTENÁRIO DO NASCIMENTO DE WILLIAM SHAKESPEARE
}

Otilia ARns

Quatrocentos anos passaram desde que, na histórica e tradicional cidade Elizabetana de Stratford-upon-Avon, nasceu aquela "fortunate child of Nature" (1), a quem Goethe chamou de "Stern der schönsten Höhe", William Shakespeare, o maior poeta e dramaturgo de língua inglêsa, com o maior sucesso poético mundial de Dante até Goethe, que foi levado à pia batismal no dia 26 de abril de 1564 .

Esste W. Shakespeare estava predestinado a empolgar o mundo inteiro por tempos duradouros, apesar das controvérsias que sempre existiram e existirão em tôrno de sua existência. Com sua educação de "small Latin and less Greek", como aponta Ben Jonson, trazendo em suas veias o germe de um gênio, vencendo as intempéries da vida literária contemporânea, Shakespeare tornou-se, mais tarde, o "man speaking to men" (2). Era preciso, no entanto, que W. Shakespeare sentisse, no âmago de seu coração de autor, o teatro, para levar, pelo teatro, sua mensagem aos corações dos homens. $O$ teatro era, portanto, o instrumento de trabalho de Shakespeare e o veículo de sua mensagem humana.

Seria Shakespeare, então, em suas obras, um narrador de histórias, um filósofo, um espelho da Natureza Humana, um poeta, um dramaturgo, ou tudo isso a um tempo só?

Vida de Shakespeare:

Que tipo de homem era William Shakespeare? Sôbre sua vida sempre pairava um ar misterioso. Sabe-se que foi levado à pia batismal a 26 de abril de 1564, que descendia da classe

(1) - M. M. Reese: "Shakespeare, His Art", 491.

12) - E. P. Alexander: "A Shakespeare Primer", 3. 
dos "Gentry" e freqüentou a escola em uma época em que ainda Vergílio e Ovídio eram as grandes metas da instrução. Sabe-se, também, que, aos 18 anos de idade, casou com uma môça de 26 e teve filhos desta união. Aos vinte e três anos de idade, deixou o torrão natal para se encaminhar na vida teatral de Londres. Embora nada conste de um matrimônio infeliz, Shakespeare lamenta, como desperdício de tempo, o periodo entre 16 e 23 anos de idade, quando diz: "I would there were no age between sixteen and three and twenty, or that youth would sleep out the rest, for there is nothing in the between but getting wenches with child, wronging the ancientry, stealing, fighting" (3).

A mocidade foi, porém, o período em que o jovem Shakespeare se decidiu para a vida. É, no entanto, difícil de se penetrar nos pensamentos e preocupações dêste jovem Shakespeare; pois, é misterioso que um dos maiores gênios criativos do mundo nada tenha escrito, pelo menos que sobrevivesse, até seus 25 anos de idade. Sabe-se, porém, que o dinheiro que ganhava, investia-o em propriedades e casas em Stratford-upon-Avon para prover seus descendentes com um patrimônio na cidade em que nascera.

Suas produções, no campo teatral, se estenderam por duas décadas e Shakespeare, então, se retirou para seu torrão natal onde morreu, em 23 de abril de 1616.

Shakespeare, o Ator e Autor:

William Shakespeare, naturalmente inclinado para a poesia e para o palco, cresceu numa cidade viva e progressista. Das ruas e dos campos de Stratford veio-lhe a experiência e nasceram os valores que Shakespeare levou pela sua vida artística afora. O povo e suas vidas, êle os observava tão fielmente, sentimentalizando ou satirizando-os, mais tarde, em suas peças, visando, por vêzes, caracteres de sua própria vivência. Foi desta cidade de Stratford-upon-Avon que Shakespeare se mudou para um mundo maior para gravar, para sempre, seu nome no cenário teatral. Londres era uma aventura para um jovem do campo, e, Shakespeare, que já possuía alguma experiência de representação na Companhia

(3) - W T III III. 
Provinciana, encontrou o teatro de Londres, recentemente organizado sob bases profissionais, invadido por um grupo de escritores a transformar as possibilidades do drama poético. Neste meio, tão condizente ao seu gênio e talento, êle, realmente, podia se considerar a "fortunate child of Nature" de seu tempo para se tornar ator, autor e comanditário de uma companhia de atôres.

Como ator era agradável e cheio de simpatia e, em virtude de sua conduta não boêmia e pelo porte nobre de sua figura, era escolhido para o papel de personagens mais representativos. Aprendeu, Shakespeare, assim, no palco, evocar risos e arrancar lágrimas e estremecimentos. Aconteceu que o ambiente teatral aliado à genialidade poética de Shakespeare fizesse que êsse ator, com sua alta sensibilidade artística e humana, acrescida de sua verbosidade inata, se tornasse, em pouco tempo, o intérprete dos anseios da alma humana.

$\mathrm{E}$, como seria o autor Shakespeare recebido no mundo literário da época?

Os oito anos de aprendizagem de Shakespeare não são um período longo para um dramaturgo cativar o auditório do centro metropolitano. Diz-se que Molière teve que viajar por mais de 10 anos pelas Províncias, antes que pudesse cativar Paris. Que Shakespeare, em 1592, obteve grande sucesso em Londres, pode ser deduzido da reação que provocou nos "University Wits", salientando-se entre êles Robert Greene. É interessante lembrar que, em uma época, sem proteção para os direitos autorais, os autores tinham que vender suas peças aos atôres. Isso, na França, também Corneille e Racine sentiram pela dura experiência. Não existia êsse problema para William Shakespeare, pois, era, como Molière, um ator de grande sucesso e dramaturgo ao mesmo tempo. R. Greene desafogou sua amargura, não porque Shakespeare fôsse ator mas, porque era agora um dramaturgo rival, surgido de um mundo desconhecido. A carta aberta que, no leito da morte, deixou aos "University Wits", aconselhando-lhes desistirem da profissão de dramaturgo para não morrerem na miséria, em benefício dos atôres, é a seguinte:

"Base minded men all three of you, if by my misere you be not warnd: for unto none of you (like mee) sought those 
burres to cleave: those Puppets (I meane) that spake from our mouths, those Anticks garnisht in our colour. Is it not strange, that I, to whom they all have beene beholding, shall (were yee in that case as I am now) bee both at once for them forsaken? Yes trust them not: for there is an upstart Crow, beautified with our feathers, that with his Tygers heart wrapt in a Players hyde, supposes he is as well able to bombast out a blanke verse as the best of you: and beeing an absolute Johannes fac totum, is in his owne conceit the onely Shakescene in a countrey... whilest you may, seeke you better Maisters; for it is a pittie men of such rare wits, should be subject to the pleasure of such rude groomes" (4).

Êste "Upstart Crow" era de memória extraordinária "never a man's thought in the world keep the roadway better than thine" (5). Shakespeare, portanto, munido dos valiosos dotes com que a Natureza o galhardeou, mais a experiência do palco recitando os melhores versos de seus contemporâneos e conhecedor do palpitar dos seus espectadores, só podia ser recebido com aplausos pelo público Elizabetano.

E um dos paradoxos do grande artista de que, para ser imortal, deve ser primeiro de sua época. E Shakespeare não teria sido para todos os tempos, se êle não tivesse sido primeiro um "craftsman" consciencioso e um verdadeiro Elizabetano, escreve M. M. Reese: "Shakespeare would not have been for all time if he had not first been a conscientious craftsman and a true Elizabethan: craftsman enough to understand and master his medium before turning its limitations to his particular and splendid uses, and Elizabethan enough to accept the thought and conventions of his age and enter imaginatively into its immediate concerns! Foi, realmente, no solo Elizabetano que se implantou o gênio de Shakespeare, tornando-se um verdadeiro representativo de seu tempo, absorvendo as influências literárias e sociais, usando-as, no entanto, à sua própria maneira, sem nunca se tornar "the mouthpiece of any of them".

Shakespeare estava consciente de que "no man can write greatly unless he is confident that he will be greatly received".

(4) - P. Alexander: Op. cit, 36.

(5) - Hen. IV, II 11. 
Esta confiança de ser bem recebido pelo auditório Elizabetano, Shakespeare possuía, pois, a preocupação constante dêste grande artista era "of providing a dish in which all could dip a spoon" (6) mas, não era o auditório Elizabetano apenas a meta do dramaturgo. Seu talento soube rasgar as limitações do ambiente Elizabetano e, com sua profunda sensibilidade humana e fôrça de imaginaçāo, penetrar na "multitudinousness of life" (7), transpondo, assim, as esferas Elizabetanas para atingir, na esfera universal: o Homem. M. M. Reese chama Shakespeare de "the flower that smiles on every one". E, sem dúvida, o poder extraordinário de identificar-se a si mesmo com a mente e os sentimentos do espectador "not all things to all men, but that particular thing that each man would have had him be" (8) que dá a fôrça e a durabilidade às obras de Shakespeare.

\section{Goethe "Zum Shakespearetag":}

Shakespeare muito surpreendeu os pesquisadores com a familiaridade que demonstra para com os mais avançados pensamentos filosóficos e a sua habilidade admirável de encorporar esta filosofia no drama poético. E notável o quanto Shakespeare absorvia em meia hora de conversa com um amigo filósofo, e, seus conhecimentos podem não ter ido muito além daquilo que usou. Como um jornalista adquire informações, Shakespeare as adquiria e provou que soube usá-las. Ninguém melhor do que Goethe, expoente máximo da literatura germânica, quando escrevia por ocasião do "Shakespearetag", podia penetrar na essência da filosofia de Shakespeare. Em seu discurso ao dia de Shakespeare, Goethe se refere à obra do poeta inglês quando diz: "Seine Plane sind, nach dem gemeinen Stil zu reden, keine Plane, aber seine Stücke drehen sich alle um den geheimen Punkt - den noch hein Philosoph gesehen und bestimmt hat -, in dem das Eigentümliche des Ichs, die prätendierte Freiheit unsres Wollens mit dem notwendigen Gang des Ganzen zusammen stösst". Esta concepção básica é reafirmada pelo Goethe da maturidade quando escreve em seu ensaio "Shakespeare und kein

(6) - M. M. Reese: Op. cit.

(7) - op cit.

(8) - op cit. 
Ende": - "Deshalb wird der Leser mit in das Bewusstsein der Welt versetzt. Sie wird für uns völlig durchsichtig: wir finden uns auf einmal als Vertraute der Tugend und des Lasters, der Grösse, der Kleinheit, des Adels, der Verworfenheit, und dieses alles, ja noch mehr, durch die einfachsten Mittel. Fragen wir aber nach diesen Mitteln, so scheint es, als arbeite er für unsere Augen; aber wir sind getäuscht: Shakespeares Werke sind nicht für die Augen des Leibes. Ich will mich zu erklären suchen. Das Auge mag wohl der klarste Sinn genannt werden, durch den die leichteste tuberlieferung möglich ist. Aber der innere Sinn ist doch klarer, und zu ihm gelangt die höchste und schnellste Utberlieferung durchs Wort; denn dieses ist eigentlich fruchtbringend, wenn das, was wir durchs Auge auffassen, an und für sich fremd und keineswegs so tiefwirkend vor uns steht. Shakespeare nun spricht durchaus an unseren innern sinn; durch diesen belebt sich zugleich die Bilderwelt der Einbildungskraft, und so entspringt eine vollständige Wirkung, von der wir uns keine Rechenschaft zu geben wissen; denn hier liegt aber der Grund von jener Täuschung, als begebe sich alles vor unsern Augen. Betrachtet man aber die Shakespeareschen Stücke genau so enthalten sie viel weniger sinnliche Tat als geistiges Wort. Er lässt geschehen, was sich leicht imaginieren lässt; ja was besser imaginiert als geschehen wird ... Durchs lebendige Wort wirkt Shakespeare, und dies lässt sich beim Vorlesen am besten überliefern; der Hörer wird nicht zerstreut, weder durch schickliche noch unschickliche Darstellung. Es gibt keinen höheren Genuss und keinen reinern, als sich mit geschlossenen Augen durch eine natürlich richtige Stimme ein Shakespearisches Stück nicht deklamieren, sondern rezitieren zu lassen" (9).

E certo que o Shakespeare Ator, sabia penetrar no âmago do coração humano pela magia da recitação. Esta magia da recitação do Shakespeare Ator penetrara nas veias do Shakespeare Autor e fêz com que a musicalidade de suas expressões repicasse e ainda repique qual sino festivo no ouvido do espectador. $\mathrm{E}$, a melodia, aliada à filosofia de suas expressões, arrasta o homem para aquêle mundo que o leitor ou espectador mais fàcilmente atinge não pelos olhos, mas pela sen-

(9) - Goethe: "Shakespeare und kein Ende". 
sibilidade. Tal a fôrça de sua expressão que Shakespeare leva o homem mais fàcilmente a imaginar o mundo de que êle é parte integrante do que ver com os olhos êste mesmo mundo de um emaranhado de virtudes e defeitos em que o amor, a fidelidade, a paciência, a coragem, o perdāo, desafiam o poder da paixão e aliviam a carga pesada da dor e do pecado. É, neste mundo cheio de paradoxos que Shakespeare sempre vê "some soul of goodness in things evil, an alloy of basenes in the most resplendent virtue", como escreve M. M. Reese, quando cita Shakespeare:

"Many of many virtues excellent:

None but for some, and yet all different...

For nought so vile, that on the earth doth live

But to the earth some special good doth give" (10).

$E$ êste algo de bondade que todo homem deve procurar no seu próximo por mais hediondos que sejam seus crimes que clamam aos céus, pois, algo de bom existe em todo homem feito à imagem e semelhança de Deus.

Não é um homem ideal que Shakespeare apresenta ao espectador mas o "mixed character, the man whose nobility or wisdom was flawed by some inadequacy in meeting the circumstances surrounding him" (11). Não era Shakespeare, portanto idealista para acreditar no poder dos meros princípios e boas intenções mas, realista, ciente de que, às vêzes, a ação falha em responder a

"The aim,

And that unbodied figure of the thought

That gave't surmised shape" (12).

E significante o que diz M. M. Reese quando escreve: "Ethically he stands among the great evangelists of Christianity. Ethically, but not spiritually; and the difference is vast, and ultimately defeating. He examined the Christian mystery and presumably, found it good, but he rejected, or did not understand, its full demands on the human spirit. He picked the flower, but was indifferent to the soil from which it grew.

(10) $-\mathrm{R}$ J II ill 1 .

(11) - M. M. R. op. cit.. 428.

(12) - T C I ill. 
If the world of his poetric imagination was on the whole a good world, it was so by the power of love; but of the love which man can give to man, not of the love which he may receive from God" (13).

A fôrça de Shakespeare não está no profundo conhecimento especulativo, nem na exaltação de uma visão espiritual, mas na segurança com que o dramaturgo trata das coisas ordinárias da vida, sem prometer felicidade além túmulo. Não esqueçamos, aqui, que a maestria com que Shakespeare aborda assuntos metafísicos e psicológicos, é a maestria de um poeta e não a de um erudito, quando êle manda "to weep for man's inhumanity to man". (14). Chorar a desumanidade do homem para com o homem, é trazer, ao homem, a mensagem mais sublime que é a mensagem cristã do Amor. Os homens devem se amar'uns aos outrost, pagar o mal pelo bem. "O amor em oposição à soberba", diz L. Borinski, "é a essência de Deus e tôdas as espécies de amor puro são semelhantes uns aos outros" (15). O amor puro de homem para homem é um passo em direção ao amor a Deus. É êsse amor a ponte que liga o homem ao além. É esta a mensagem mais sublime que o maior dos poetas, o "Stern der schönsten Höhe", segundo Goethe, pôde legar à humanidade.

\section{Shakespeare e suas obras:}

Já se tornou tradicional, nas histórias das literaturas mundiais, de se encontrar um superlativo diante do nome de Shakespeare, como o maior poeta de todos os tempos e nações. Filólogos já se deram o trabalho de contar as palavras que Shakespeare usou em suas obras e o resultado da pesquisa lhes mostrou que Shakespeare é, realmente, o poeta cujo tesouro de expressões é o mais amplo jamais usado no mundo (16). Prova maior ainda do que a riqueza de palavras de Sakespeare é, no entanto, o vigor de suas expressões. Não significa isso que a genialidade de Shakespeare não tenha passado por fases de formação. O jovem Shakespeare aprendeu seu ofício no repertório londrino, enquanto retocava mais do que pro-

(13) - M. M. Reese, op. cit., 451.

(14) - M. M. Reese, op. cit., 43.

(15) - L. Borinsk1: "Dle Neueren Sprachen", 195.

(16) - E. Laaths: "Geschichte der Weltliteratur", 348. 
duzia, com originalidade, a trilogia de "Henry VI" e "Titus Andronicus". Marlowe, seu maior predecessor, não dava valor à vida do homem ordinário, mas Shakespeare aceitava a ordem moral e as leis imutáveis do universo, mostrando interêsse para integrar-se nos afazeres diários de tôdas as classes dos homens.

$E$, no entanto, com timidez e modéstia, que Shakespeare redige sua carta de petição de padrinho, ao Conde de Southhampton. Era o poema "Venus and Adonis" que êle dedicava com a convicção de ter produzido um poema que lhe dava esperanças para um futuro prometedor, quando escreve:

"To The

Right Honorable Henrie Wriothesley,

Earle of Southhampton, and Baron of Titchfield Right Honourable,

I know not how I shall offend in dedicating my unpolisht lines to your Lordship, nor how the worlde will censure mee for choosing so strong a proppe to support so weake a burthen, one lye if your Honour seeme but pleased, I account my selfe highly praised, and vowe to take advantage of all idle houres, till I have honoured you with some graver labour. But if the first heire of my invention prove deformed, I shall be sorie it had so noble a god-father: and never after eare so barren a land, for feare it yeeld me still so bad a harvest, I leave it to your Honourable survey, and your Honor to your hearts content which I wish may alwaies answere your owne wish, and the worlds hopefull expectation.

Your Honors in all dutie,

William Shakespeare".

No poema "Venus and Adonis" Shakespeare já demonstra a sua grande sensibilidade humana, mesmo com as criaturas mais ínfimas, quando, por exemplo, descreve o caracol recolhendo-se, com dôr, para dentro de sua concha:

"... the snail, whose tender horns being hit, backward in his shelly cave with pain, 
And there, all smoth red up, in shade doth sit, Long after fearing to creep forth again" (17).

Foi tão cordial a receptividade da dedicatória que, no ano seguinte, para o segundo poema "Rape of Lucrece", Shakespeare já escreve com segurança: "The love I dedicate to your Lordship is without end". Seu verdadeiro patrôno, no entanto, foi, sem dúvida, o público que o aplaudia e estimulava para novas prođuções.

A genialidade de Shakespeare já desponta nos anos sucessivos quando o jovem poeta consegue objetividade dramática em suas obras-mestras "Richard III" e "Romeo and Juliet".

"Richard III", é verdade, sofre ainda a influência do "Tamburlaine" de Marlowe. O ambiente oriental de Marlowe é, no entanto, transportado, por Shakespeare, para o Oriente - um ambiente mais achegado e, por isso, mais palpável pelo público Elizabetano e, conseqüentemente, de maior sucesso. O rei Ricardo III, ambicioso, sanguinário, traidor, assassino e usurpador da coroa, é um dos extremos de "things evil" que, no entanto, pela pintura mágica do verso de Shakespeare, antes clama admiração pela estranha energia do herói do que pela sua crueldade e crimes, confirmando, assim, que, neste mundo paradoxal, para Shakespeare existe como deve existir para o homem, "some soul of goodness in things evil".

O esplendor, a poesia e a compaixão, apresentados com originalidade surpreendente em "Romeo and Juliet", não se encontram ainda prefigurados em nenhuma obra inglêsa anterior. \& com grande naturalidade que Shakespeare traz, ao palco, uma passagem ordinária da vida. E o amor palpitante entre dois jovens, filhos únicos de famílias riquíssimas de Verona, que se amam, loucamente, apesar da inimizade existente entre elas. É com a segurança das expressões significativas de seus versos que Shakespeare faz chorar o coração do espectador pela desumanidade do homem para homem, quando Juliet, em desespêro, exclama:

Jul. "Tis but thy name that is my enemy; Thou art thyself, though not a Montague.

(17) - VA, 1033-36. 
What's Montague? It is nor hand, nor foot, Nor arm, nor face, nor any other part Belonging to a man. $O$, be some other name! What's in a name- That which we call a rose By any other name would smell as sweet, So Romeo would, were he not Romeo call'd, Retain that dear perfection which he owes Without that title. Romeo, doff thy name; And for thy name, which is no part of thee, Take all myself.

Rom. I take thee at thy word:

Call me but love, and I'll be new baptiz'd;

Henceforth I never will be Romeo" (18).

Uma beleza trágica transfigura os jovens que se amam levando seus pais à reconciliação sòmente na morte. Os filhos, mortos, lado a lado, lhes fazem lembrar que

"None... so vile, that on the earth doth live, But to the earth some special good doth give".

A estas produções do jovem Shakespeare, acrescente-se, ainda, a perfeição de "A Midsummer Night's Dream", a peça das máscaras da côrte removidas para o mundo encantado.

A madureza nas obras de Shakespeare já aparece na trilogia "Richard III" e "Henry IV" (1 e 2) em que o poeta desfralda a idéia do homem rei: $O$ Rei por índole; o Rei rebelde e o alegre, despreocupado príncipe Henrique que, no fim, se mostra o elevado homem do equilíbrio em quem a personalidade e a função se completam.

Associam-se ao grupo de dramas históricos ainda "King John" e "Henry V".

Nos dramas históricos, a genialidade Shakespeareana já atingira completa independência. Shakespeare nāo mantém tese histórica ou política que lhe exigisse representar o errado como certo ou o injusto como justo. Nem atenua o dramaturgo, as loucuras ou os crimes do passado, tratando, como suas conseqüências, ọ eventos mais felizes que, às vêzes, surpreendem gerações posteriores. Ninguém mais do que Shake-

(18) - R J II, 11 . 
speare deu ênfase à parte representada na história pela personalidade humana; mas, também, ninguém, jamais, compreendeu mais claramente aquelas fôrças incalculáveis e misteriosas que contribuem para a sorte dos Estados e de seu povo. Shakespeare não pretendia entender tôda a verdade. O que Shakespeare entendia era que êle tinha nascido em uma hora afortunada e em uma terra muito favorecida, embora a maneira de considerar a história de seu país sempre revele algo de sua própria fé e esperança.

A exuberância criativa das comédias de Shakespeare dá, às vêzes, realidade aos obstáculos do caminho à felicidade que divide ou distrai o nosso interêsse. Esta fôrça imaginativa, muitas vêzes, dá à comédia de Shakespeare uma vitalidade perturbante, assim que avança para a maturidade. Ele parece brincar com as tarefas leves demais para o exercício próprio da exuberância de seu poder.

Por volta do século, Shakespeare parece ter sofrido um abater nos seus sentimentos que é, muitas vêzes, explicado por experiências pessoais ou acontecimentos políticos. E nos seus Sonetos que transparece uma confusão trágica interior. Cento e vinte e seis sonetos são dirigidos a um jovem amigo, enquanto vinte e oito cantam a paixão de amor por uma mulher de cabelos negros. Nos Sonetos dirigidos ao jovem, transforma-se o amor terreno em uma adoração de beleza. Os vinte e oito Sonetos, dirigidos à amada escura, refletem o terrível tormento da infidelidade da mulher, que, finalmente, apanha o jovem amigo na rêde da sedução, como demonstra o sonêto 144:

"Two loves I have, of confort and despair, Which like two spirits do suggest me still; The better angel is a man right fair, The worser spirit a woman colour'd ill. To win me soon to hell, my female evil Tempteth my better angel from my side, And would corrupt my saint to be a devil, Wooing his purity with her foul pride. And whether that my angel be turn'd fiend, Suspect I may, yet not directly tell; But being both from me, both to each friend, 
I guess one angel in another's hell.

Yet this shall I ne'er know, but live in doubt, Till my bad angel fire my good one out".

"Venus and Adonis", "The Rape of Lucrece" Shakespeare mesmo os publicou, e os Sonetos apresentam o maior valor estético, não só das obras de Shakespeare, mas até dentre a literatura mundial.

Naturalmente, pode existir uma relação entre os Sonetos e aquelas produções mais sombrias que Shakespeare agora traz ao palco. No "The Merchant of Venice" reina ainda o bom humor, embora o judeu Shylock, revestido de traços diabólicos, talvez, lembre "The Jew of Malta" de Marlowe. Nessa obra de Shakespeare a expressão é mais poética do que dramática. Já em "Julius Caesar" observa-se uma justiça dramática, pura. O retrato de César é, sob linhas tão assustadoramente calculadas em favor de Brutus, que nós sentimos uma perda de objetividade que obscurece a finalidade. "Julius Caesar" é, no entanto, sob muitos aspectos, um estudo preparatório para "Hamlet", e, aqui, Shakespeare conseguiu a completa solução de seu problema. Talvez a tragédia "Hamlet" possa ser encarada sob a concepção "Totenkult" ou "Heroenkult", culto êsse mais antigo do que Homero, na palavra de G. Hauptmann: "Vielleicht gehört das ganze Stück unter den Begriff. Totenkult. Dieser ist älter als Homer. Statt Totenkult setze ich lieber gleich Heroenkult. Die Seele eines grossen Toten muss, besonders wenn dieser durch Mord oder Meuchelmord ums Leben gekommen ist, versöhnt werden, da sein zorn und die Macht, ihn durchzusetzen, sonst verheerend sind. ... In diesem Shakespearischen Hamlet steckt, unbewust erstanden, seelenkultisch sozusagen erstanden, ein antik-heroisches Leichen spiel" (19).

Em obras anteriores Shakespeare nãó tinha ido além das dúvidas surgidas pela violação da ordem e da descoberta da verdadeira natureza do homem escondido atrás da armadilha. Em "Hamlet", êle usa o velho melodrama da vingança para pintar a agonia de uma mente sensitiva. Hamlet, o personagem, é o instrumęnto de vingança do terrível espírito de seu pai, o rei assassinado. Este espírito, tornado herói, exige ex-

(19) - E. Lasths: op. c1t. 354. 
piação e vingança de seu inimigo e sòmente o sangue o reconcilia. Visto dêste ponto de vista, o herói torna-se um espírito terrível, temível, irreconciliável e vingativo que, com fúria, sem escolha, extingue o bom e o mau, a culpa e a inocência. E, sob a pressão terrível dêste espírito, que o jovem Hamlet investiga a diferença entre aparência e realidade. "He knows not seems". É o segundo casamento apressado de sua mãe que, depois de um ato de incesto com seu tio, levanta suspeitas na mente de Hamlet. A intensidade de sua dor tem lhe iluminado a verdade impalpável que forma a base de tôdas as belas profissões de amor, de virtude e lealdade. O primeiro dos seus solilóquios leva à convicção ortodoxa de que os indivíduos sendo perversos, o universo físico e o govêrno também são corruptos e doentes. Por causa do pecado de sua mãe e o pecado, que já suspeita de seu tio, o céu está "thought-sick". As revelações do espírito completam sua desilusão. A linguagem de Hamlet vive agora no contraste agonizante entre o que o homem deve ser e o que é, uma tragédia existencialista do homem moderno em que a tristeza da isolação e do isolamento se elevam até o nihilismo: um nihilismo que se submete à prova do único incontestável e irrefutável Deus, a Majestade da morte. Hamlet é, assim, o "Prototyp der modernen Gefüls-Bewustseinslage" (20).

Picantes são os versos de Hamlet quando êste se encontra com Rosencrantz e Guildenstein:

"What is a man,

If his chief good and market of his time

Be but to sleep and feed? A beast, no more.

Looking before and after, gave us not

That capability and god-like reason

To fust in us unus'd" (21).

No solilóquio "to be or not to be", a agonia pessoal de Hamlet se estende para o universal, para tôda a humanidade arruinada. No clímax de sua tragédia Shakespeare atinge a maturidade emocional que revela a tragédia além de sua própria experiência. Os males sôbre os quais medita, neste solilóquio, vão bem além da côrte da Dinamarca.

(20) - E. Laaths, op. cit., 355.

(21) - Ham IV. 
Hamlet, agora, depois de suas aventuras no mar para onde seu tio o mandara, não é mais aquela vítima injuriada pelas suas próprias dificuldades. Èle descobriu, pela amarga experiência, que

"There's a divinity that shapes our ends, Rough-hew them how we will!" (22).

Não foi a teoria, mas a dura experiência da vida, que lhe fez sentir que, atrás da vontade do homem está sempre Deus. Hamlet, com o espírito transformado exalta e aceita a morte inevitável. Morte significa, agora, para êle, nada mais do que a prontidão de encontrar o silêncio, a felicidade.

"Hamlet", a tragédia em que Shakespeare encontrou solução para seu problema, sobrevive, mesmo fora da poesia que leva seu nome. Elle se tornou, como os heróis da antiguidade e como o "Dom Quijote", o "Faust", um mito por si mesmc sôbre o qual os tempos continuam a poetizar.

Naturezas míticas semelhantes Shakespeare as criou mesmo antes e depois de "Hamlet". Isso vale para "Othello", onde Shakespeare mostra o poder de um homem a envolver todos os outros na corrupção que constitui sua visão diária do universo; para "Macbeth", a tragédia da cobiça do poder em dimensões sobrenaturais; para "King Lear", a tragédia da pruciente vaidade humana, a absoluta dignidade real que acaba com a destruição de tôda uma geração.

Intercalam-se, aí, algumas obras problemáticas como "Troilus and Cressida", a comédia "All's Well That Ends Well", o drama problemático "Measure for Measure", "Antony and Cleopatra", um retrato da época e, ao mesmo tempo, um mistério do terrivel poder de Eros; "Coriolanus" - o trágico descalabro da nobreza em um mundo de baixeza ou do comércio sagaz. Em "Timon of Athens" Shakespeare apresenta o homem que nada aprendeu de seus sofrimentos. É a "most Jacobean" das obras de Shakespeare, embora a visão poética que encorporou em "Hamlet", tenha sido uma constante durante sua tragédia madura. $O$ que diferencia Shakespeare de seus contemporâneos que exploraram a posição do homem num universo enfraquecido pela corrupção, é

(22) - Ham. V 11 . 
que Shakespeare não acreditava na fatalidade desta enfermidade. Shakespeare explorou o ponto de vista do pessimismo da humanidade sòmente para reafirmar os valôres positivos que asseguram, ao homem um lugar privilegiado num mundo criado para o homem de aspirações mais elevadas.

Shakespeare encerra suas produções com "Cymbeline", "The Winter's Tale" e "The Tempest". Nestas obras a música é para Shakespeare não apenas uma arte humana de sons, mas uma fôrça pitagórica do universo que age entre as almas $\varepsilon$ as estrêlas. Embora se lhe ainda atribua "Henry VIII", é pelo discurso festivo de Próspero, imagem de Shakespeare, que ordena os espíritos elementares debaixo e por cima da terra que Shakespeare se despede do palco e da poesia:

Pro. Ye elves of hills, brooks, standing lakes and And ye that on the sands with print less groves; Do chase the ebling Neptune, and do fly him When he comes back; you demi-puppets that By moonshine do the green sour ringlets make, Whereof the ewe not bites; and you whose pastime Is to make midnight mushrooms, that rejoice To hear the solemn curfew; by whose aid Weak masters though ye be - I have bedimm'd The moontide sun, call'd forth the mutinous winds And'twixt the green sea and the azu'd vault Set roaring war. To the dread rattling thunder Have I given fire, and rifted Gove's stout oak With his own balt; the strong-bas'd promontory Have I made shake, and by the spurs pluck'd up The pine and cedar. Graves at my command Have wak'd their sleepers, op'd, and let'em forth, By my so potent art. But this rough magic I here abjure; and, when I have requir'd Some heavenly music-which even now I do To work mine end upon their senses that This airy charm is for, I'll break my staff, Bury it certain fathoms in the earth, And deeper than did ever plummet sound I'll drown my book. (solemn music) (23).

(23) - The Tempest V 11 . 
Há, na literatura universal, gênios que não interpretaram apenas as suas próprias vivências, mas tornaram-se intérpretes dos mais profundos anseios da alma humana, de tal forma que nêles se fundamenta o próprio arcabouço de tôda literatura. Assim, não seria possível imaginar, não apenas a literatura de língua inglêsa, mas ainda da nossa civilização ocidental, sem êste intérprete máximo dos anseios do homem moderno que foi William Shakespeare. Não foi êle um filósofo, um narrador de histórias, um compositor de dramas, comédias e tragédias mas, usando os gêneros literários que estavam à mão como instrumentos, soube Shakespeare transmitir mais que uma mensagem a mais profunda interpretação daquilo que é o próprio objeto da literatura: A grandeza e os abismos da alma humana, na harmonia e na perfeição que só foi dado ao gênio transmitir na palavra e na música. A efeméride de seu nascimento, há 400 anos, não representa senão um acidente imperceptivel diante da grandeza da obra que relegou à humanidade que sempre o considerará um dos intérpretes máximos dos mistérios que os homens de tôdas as épocas revivem, quando se apercebem, com temor, de sua própria grandeza.

\section{BIBLIOGRAFIA}

1. Alexander, P.: "A Shakespeare Primer". London. James Nisbet and Co. Ltd.

2. Borinski, L.: "Die Neueren Sprachen".

3. Gorrett, J.: “Talking of Shakespeare". London, Nodder \& Stoughton.

4. Goethe, J. W.: "Zum Shakespearetag", "Shakespeare u. Kein Ende".

5. Laaths, E.: "Geschichte der Weltliteratur".

6. Legouis \& Cazamian's: "History of English Literature". London.

7. Reese, $M$. $M$.: "Shakespeare, His World and His Art". London.

8. Shakespeare: Complete Works. London and Glasgou. Collins.

OBRAS DE SHAKESPEARE

$\begin{array}{ll}1590-1 & 2 \text { HENRY VI } \\ & 3 \text { HENRY VI } \\ 1591-2 & 1 \text { HENRY VI }\end{array}$




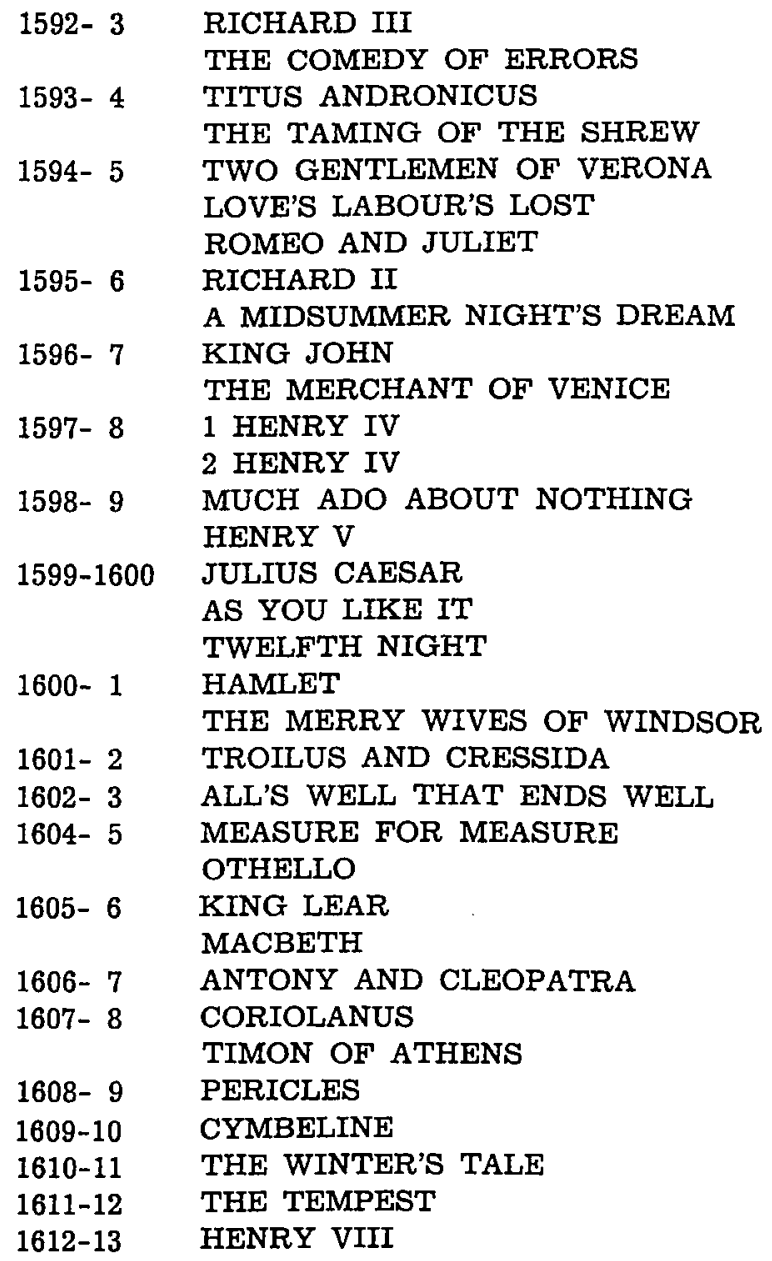

POEMAS

1592- 3 VENUS AND ADQNIS

1593- 4 THE RAPE OF LUCRECE

1595- 9 THE SONNETS

1600 THE PHOENIX AND TURTLE 